\section{KT JUE UNIVESITY of Sedimentologic and Stratigraphic Controls on Reservoir Sweet Spots in Wolfcamp 'A,' Howard County, Midland Basin}

\begin{tabular}{|c|}
\hline \begin{tabular}{l}
\multicolumn{1}{|c}{ Significance } \\
- Deep-water carbonates can comprise \\
conventional and unconventional \\
hydrocarbon reservoirs and non-reservoir \\
rocks. \\
- Such deposits are complex, and not as \\
well understood as siliciclastic deposits \\
and shallow-water carbonates. \\
- The economic potential warrents further \\
exploration of the controls on the \\
distribution of reservoirs in order to \\
create predictive models that are widely \\
applicable.
\end{tabular} \\
\hline $\begin{array}{l}\text { Overview } \\
\text { - Deep-water deposits of “Wolfcamp A" ar } \\
\text { investigated as a case study to understand } \\
\text { the sedimentologic and stratigraphic } \\
\text { controls on 'sweet spots' within basinal } \\
\text { settings of the Midland Basin. } \\
\text { This project will provide an understandin } \\
\text { of the compositional, sedimentologic, and } \\
\text { stratigraphic characteristics of sweet spots } \\
\text { in the Wolfcamp A. }\end{array}$ \\
\hline \begin{tabular}{l}
\multicolumn{1}{c}{ Methods } \\
1) Compare petrophysical, XRD, and \\
pyrolysis data in Wolfcamp A to determine \\
what variables control reservoir qualilty. \\
2) Decipher depositional processes of \\
units. \\
3) Determine the vertical and lateral \\
stratigraphic archititecture of Wolffamp A. \\
4) Generate a stratigraphic and \\
sedimentologic conceptual model to locate \\
reservoir sweet spots.
\end{tabular} \\
\hline
\end{tabular}

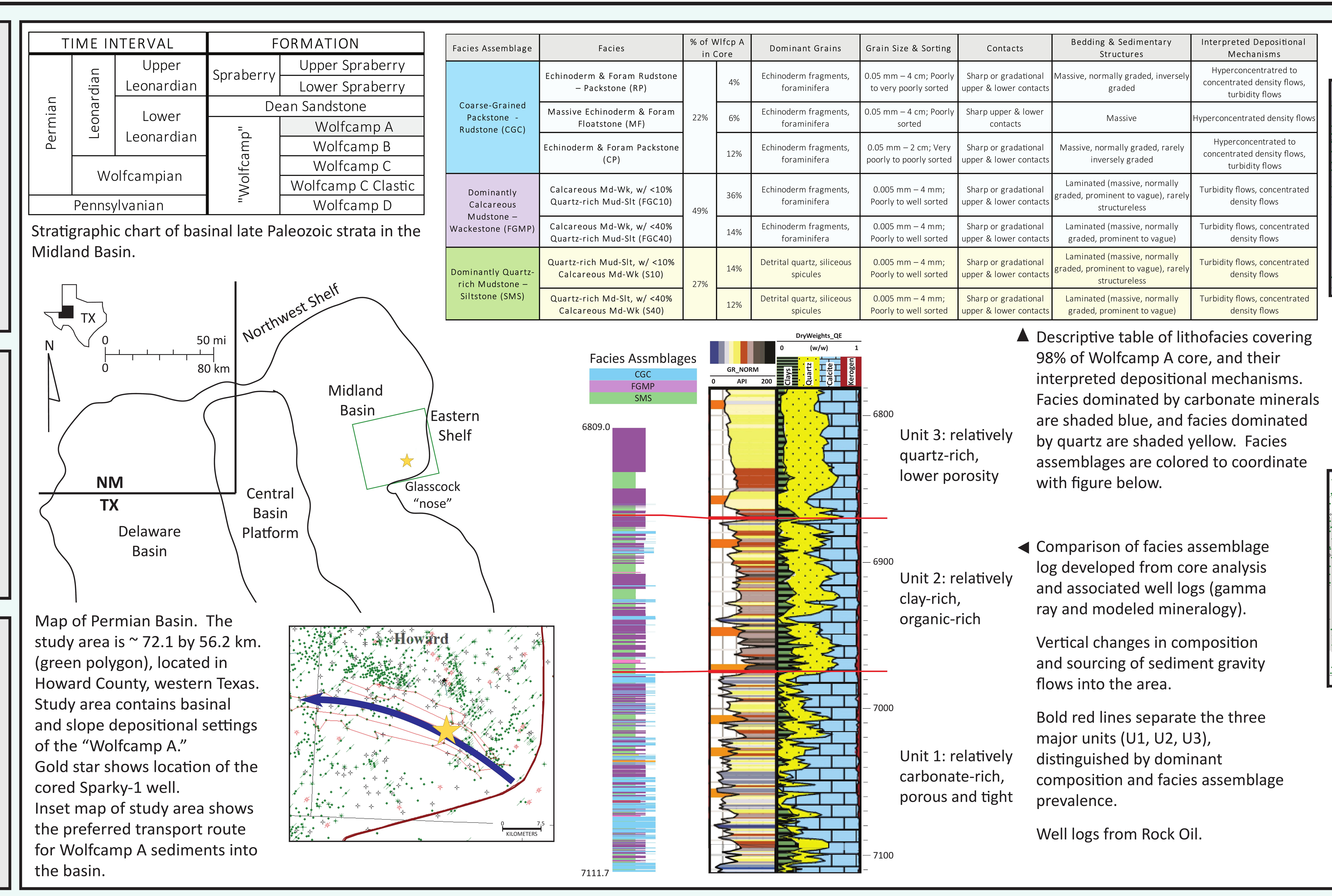

\section{KICC}
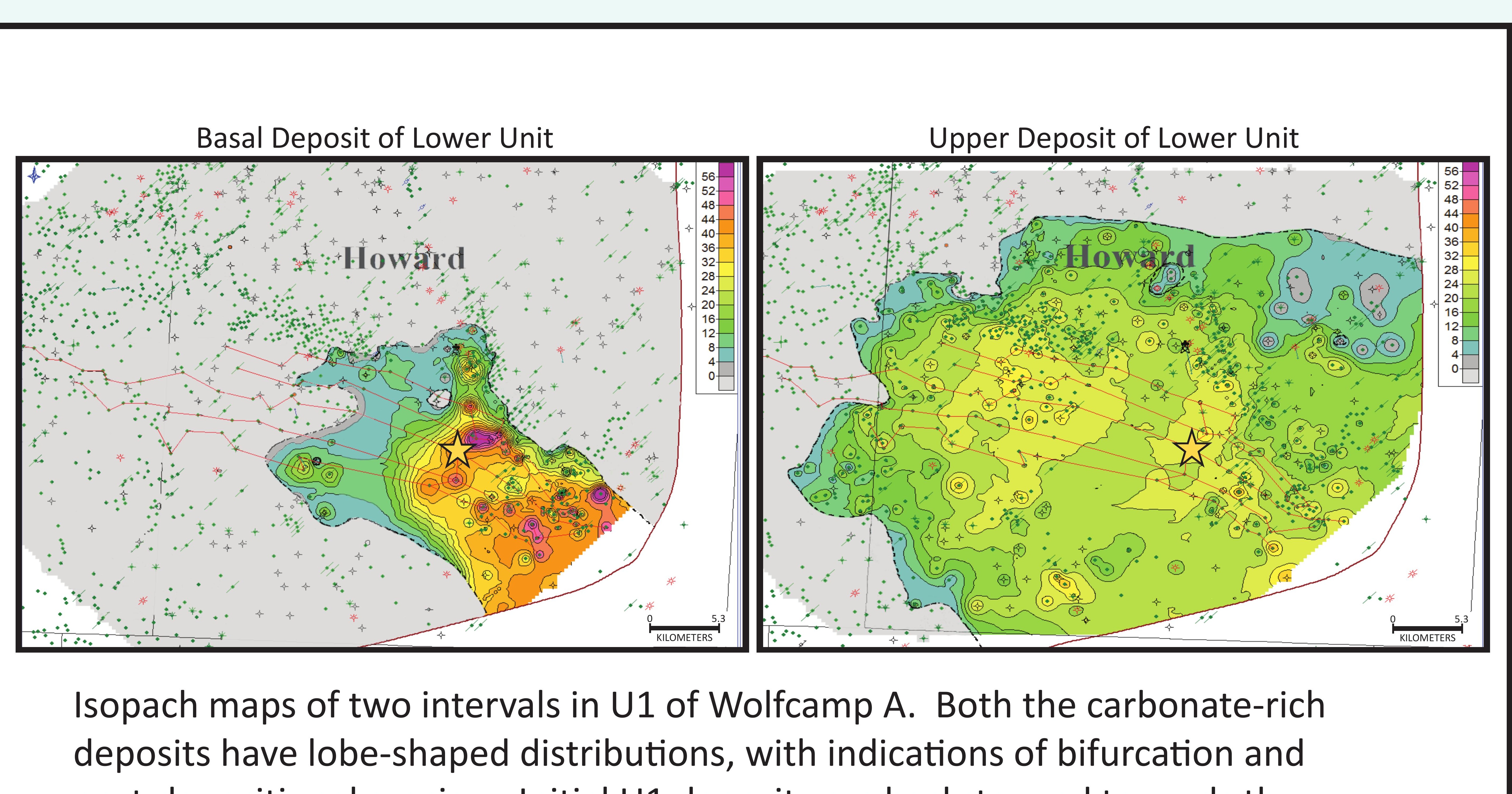
deposits have lobe-shaped distributions, with indications of bifurcation and
post-depositional erosion. Initial U1 deposits are backstepped towards the platform margin. Subsequent U1 deposits prograde towards the basin. Gold
star in each map shows location of the Sparky-1 well.

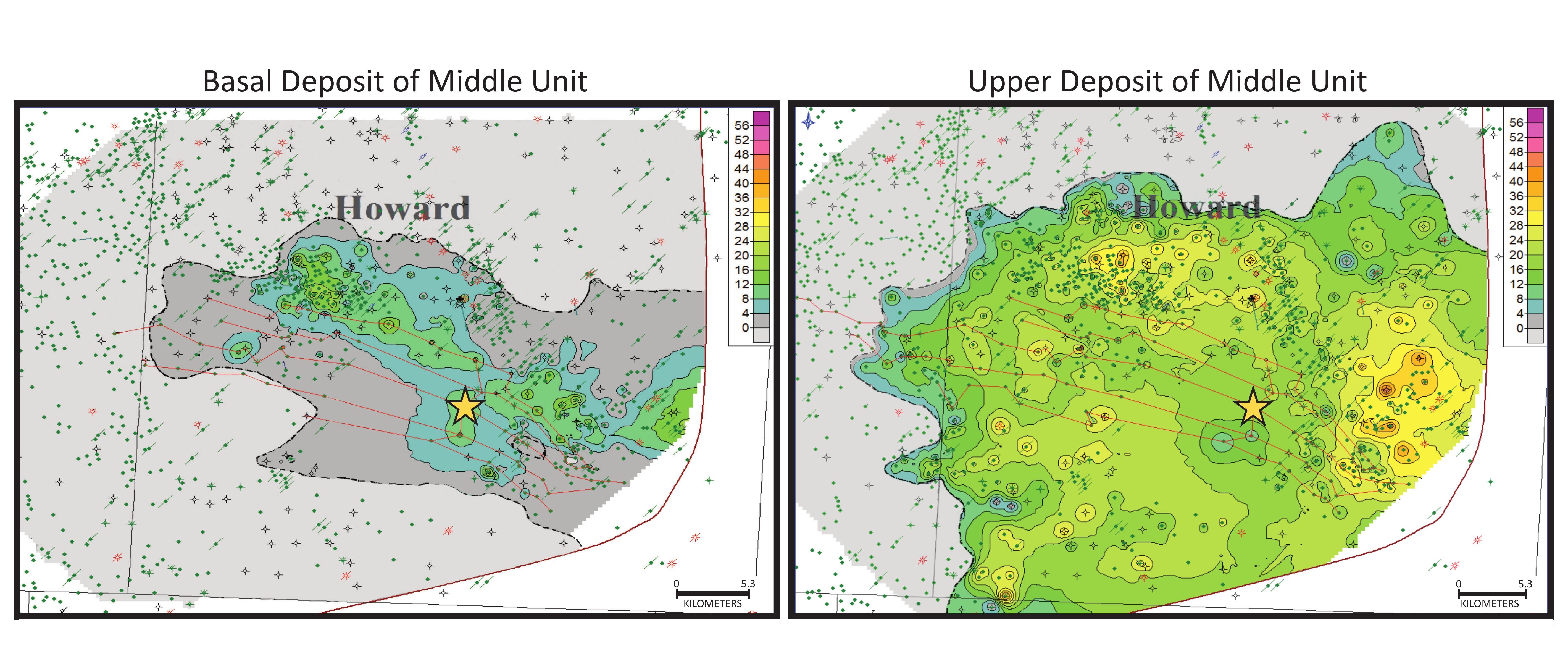

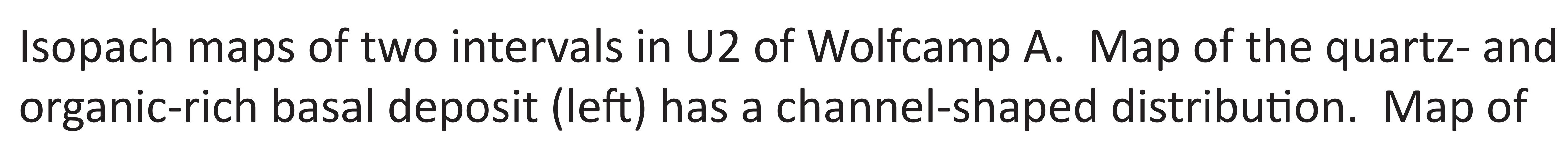
the quartz-and carbonate-rich upper deposit trighth has a lobe-shaped distribution, with indications of bifurcation and post-depositional erosion.
litial deposits of $U$ a are backstepped towards the platrorm margin

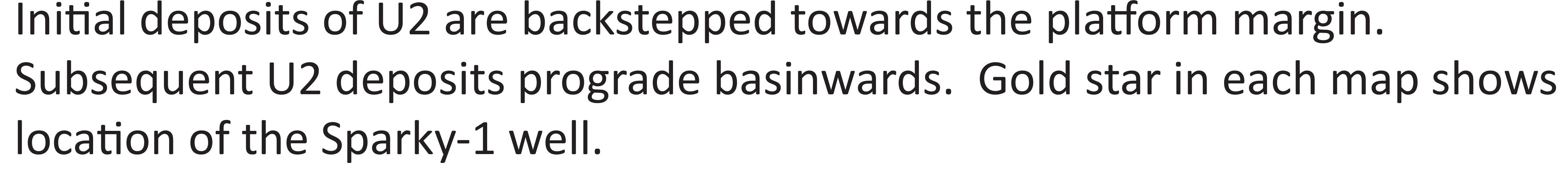

Key Findings To Date - Eleven carbonate- or quartz-rich lithofacies, interpreted to represent sediment gravity flow deposits from
multiple platform sources.

- Quartz-rich mudrocks form most promising unconventional reservoirs, and grainy resedimented carbonates form reservoirs with macropores. - U1 is dominated by carbonates, distributions extending basinward. - U2 basal deposits are dominated by quartz-rich mudrocks occurring in channels, backstepped towards the platform margin. Subsequent and extend basinwards.

- A preferred transport route for

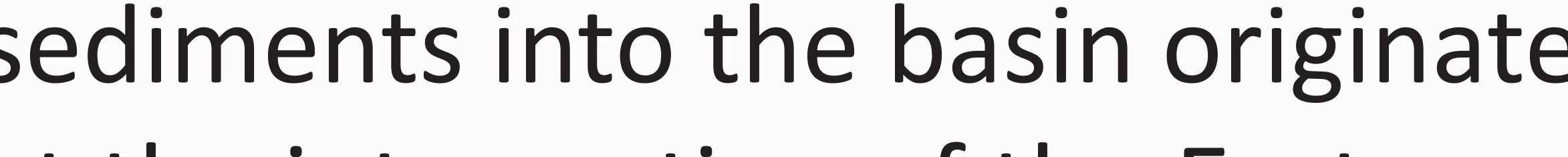
\begin{tabular}{l} 
Shelf and Glasscock "nose." \\
\hline
\end{tabular}

\section{Implications}

- The vertical change in dominant composition from carbonate to quartz, progradational geometries punctuated by backstepping of deposits between major units, and external controls, such as rest (

$=$
mudrock deposits are lobe-shaped
and extend basinwards. 